\title{
Combined Vibrational Spectroscopic and Quantum Chemical Investigations of 1,8-diaminooctane
}

\author{
Akif Özbay $^{1 *}$, Aysun Gözütok $^{2}$ \\ ${ }^{1}$ Gazi University, Faculty of Science, Department of Physics, Ankara, Turkey \\ ${ }^{2}$ Selçuk University, Faculty of Science, Department of Physics, Konya, Turkey \\ *aozbay@gazi.edu.tr \\ Received: 06 December 2018 \\ Accepted: 18 January 2019 \\ DOI: $10.18466 /$ cbayarfbe. 492861
}

\begin{abstract}
This paper contains the molecular parameters, vibrational properties and some theoretical calculations of 1,8-diaminooctane. Bond angles, bond lengths, vibrational properties, dipole moments, frontier molecular orbitals and molecular electrostatic potential of 1,8-diaminooctane were performed with using density functional theory calculations with B3LYP/6-311++G(d,p) level of theory. Vibrational properties were interpreted with the by using scaled quantum mechanical force field. This study enables us to figure out the vibrational and structural properties and some electronic properties of the 1,8-diaminooctane by means of the theoretical and experimental studied methods.
\end{abstract}

Keywords: 1,8-diaminooctane, density functional theory, theoretical calculations, molecular electrostatic potential.

\section{Introduction}

This molecule concerns of the monoalkylamines which are organic compounds including a primary aliphatic amine group. An alkane- $\alpha$ and $\omega$-diamine in which the two amino groups are separated by eight methylene groups [1]. The 1,8-diaminooctane is used as cross link effects while the synthesis of various molecular carbon nanotubes and macrocycle molecules [2]. Aliphatic diamines are important compounds that are widely used in coordination chemistry, biochemistry and polymer chemistry. This molecule has a fundamental carbon chain structure. So, it is used like synthesis molecule. This molecule is used as the ligand in the formation of Hofmann type host-guest compounds. Molecular formula of 1,8-diaminooctane is $\mathrm{C}_{8} \mathrm{H}_{20} \mathrm{~N}_{2}$ and be found in solid phase.

FT-IR spectra of 1,8-diaminooctane was reported by Kasap and Özbay [3]. In that study, this molecule had been purchased from Sigma-Aldrich and used without further purification. IR spectra of 1,8-diaminooctane had been recorded 400-4000 $\mathrm{cm}^{-1}$ with Perkin-Elmer Spectrum One FT-IR spectrometer.

In our study, the molecular structure (bond angles, bond lengths, dipole moments) and vibrational frequencies of 1,8-diaminooctane have been calculated by density functional theory (DFT) with B3LYP method and 6$311++\mathrm{G}(\mathrm{d}, \mathrm{p})$ level of theory.

\section{Materials and Methods}

In this study, 1,8-diaminooctane molecule was drawn in three dimensions using the molecular drawing program GaussView 3.0 [4]. The geometrical parameters of this structure were automatically entered as input data in the Gaussian 03W package program [5]. Then, 1,8diaminooctane molecule were optimized by means of the B3LYP/6-311++G(d,p) level of theory. Bond angles, bond lengths and vibrational frequencies of 1,8diaminooctane molecule have been calculated DFT/B3LYP with $6-311++G(d, p)$. The vibrational frequencies of the optimized geometry were corrected by multiplying with scaling factors [6] for comparing the experimental values. The optimized geometrical structure of the title molecule is shown in Figure 1.

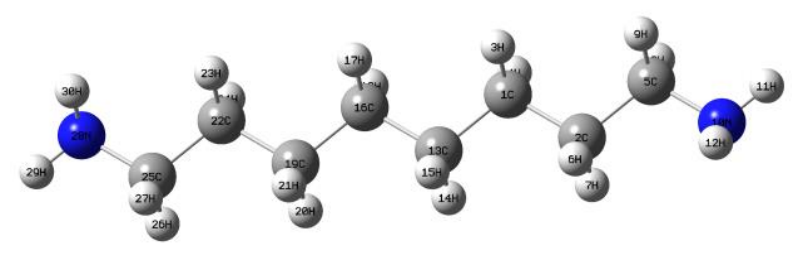

Figure 1. Molecular structure and atomic numbering of 1,8-diaminooctane.

Since there is not published experimental data on the bond lengths and bond angles of the 1,8-diaminooctane, the calculated geometrical parameters of this molecule were compared with the experimental values of the geometrical parameters of the 1,6-diaminohexane molecule as similar molecule performed by Meng and 
Lin [7].

The potential energy distribution (PED) was calculated via using the scaled quantum mechanics (SQM) program [8] and the fundamental vibrational modes were assigned with their PED values.

Addition to these properties, HOMO-LUMO energy gap and MEP have been calculated by DFT/B3LYP with same basis set.

\section{Results and Discussion}

\section{Geometrical parameters}

The experimental values and the calculated geometrical parameters of 1,8-diaminooctane were compared in Table 1.

In the B3LYP/6-311++G(d,p) level of theory, the N-C-C $\left(116.49^{\circ}\right)$ bond angle is greater than the C-C-C $\left(113.65^{\circ}\right)$, $\mathrm{H}-\mathrm{N}-\mathrm{H}\left(104.78^{\circ}\right)$ and $\mathrm{H}-\mathrm{C}-\mathrm{H}\left(106.21^{\circ}\right)$. In general, the $\mathrm{N}-\mathrm{C}-\mathrm{C}$ bond angles are greater than the $\mathrm{C}-\mathrm{C}-\mathrm{C}, \mathrm{H}-\mathrm{C}-\mathrm{H}$ and $\mathrm{H}-\mathrm{N}-\mathrm{H}$ bond angles. This is also consistent with the experimental results.

In the B3LYP/6-311++G(d,p) level of theory, the C-C $(1.54 \AA)$ bond length is greater than the N-C $(1.48 \AA)$, C$\mathrm{H}(1.10 \AA)$ and N-H (1.03 $\AA)$. In general, the C-C bond lengths are greater than the $\mathrm{N}-\mathrm{C}, \mathrm{C}-\mathrm{H}$ and $\mathrm{N}-\mathrm{H}$ bond lengths. This is also consistent with the experimental results.

Our calculated the geometrical parameters were found to be very compatible with compared experimental the geometrical parameters.

Table 1. Experimental and calculated parameters of 1,8diaminooctane.

\begin{tabular}{ccc}
\hline Bond Lengths $(\AA)$ & B3LYP/6-311++G(d,p) & Experimental $^{[7]}$ \\
\hline N-H & 1.03 & 0.90 \\
C-H & 1.10 & 0.97 \\
N-C & 1.48 & 1.48 \\
C-C & 1.54 & 1.51 \\
\hline Bond Angles $\left(^{\circ}\right)$ & & \\
\hline H-C-H & 106.21 & 107.59 \\
H-N-H & 104.78 & 107.69 \\
N-C-C & 116.49 & 114.71 \\
C-C-C & 113.65 & 112.01
\end{tabular}

1,8-diaminooctane molecule has 30 atoms in which the $\mathrm{C}$ and $\mathrm{N}$ atoms are planar and the $\mathrm{H}$ atoms are out of plane. This molecule belongs to the point group $\mathrm{C}_{2 \mathrm{~h}}$. Since this molecule is a non-linear molecule, it has 84 normal vibrational modes.

\section{Vibrational Assignment}

The vibrational frequencies and IR vibrational intensity are given in Table 2. The experimental and calculated FT-IR and FT-Raman spectra for 1,8-diaminooctane are given in Figures 2-4. Also, the corresponding data are given in Table 2.

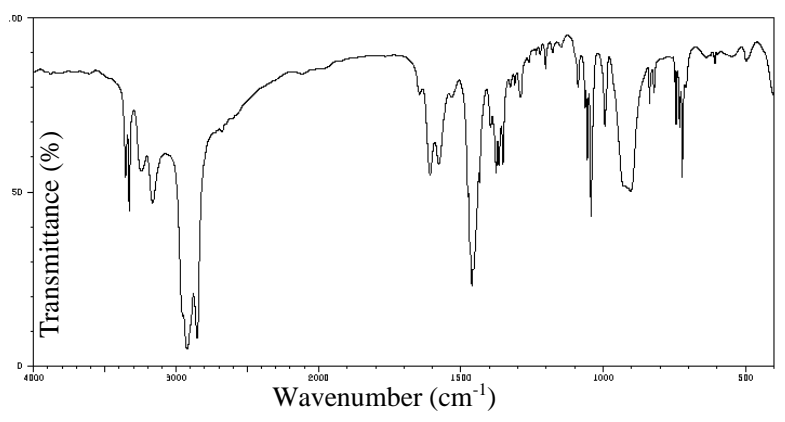

Figure 2. Experimental FT-IR spectra of 1,8diaminooctane.

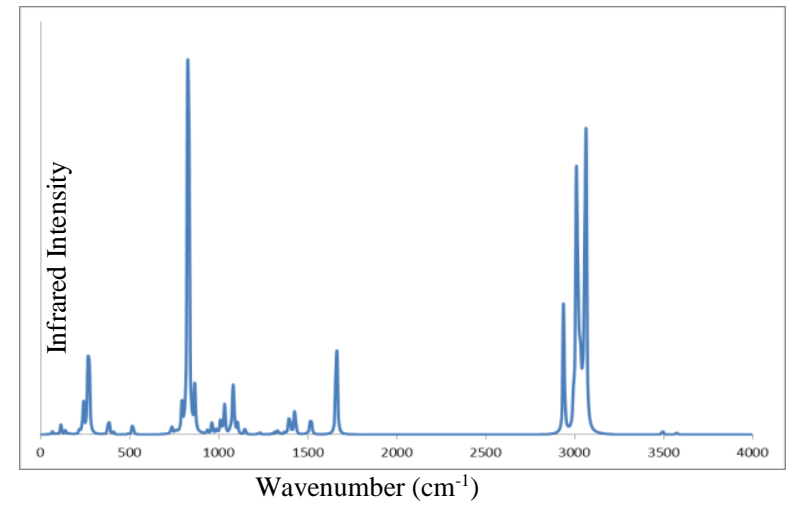

Figure 3. Theoretical FT-IR spectra of 1,8diaminooctane.

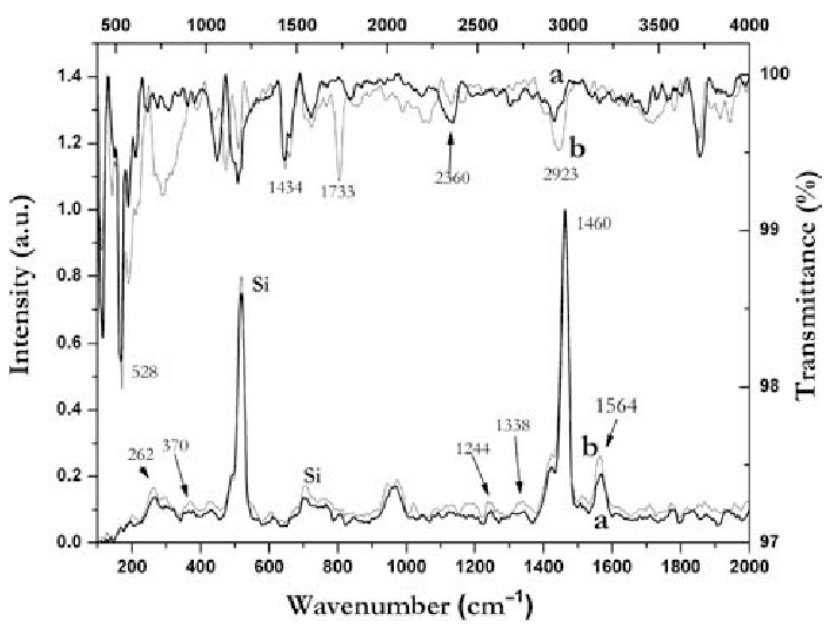

Figure 4. Experimental and theoretical FT-Raman spectra of 1,8-diaminooctane.

Table 2. The vibration frequencies of 1,8-diaminooctane molecule.

\begin{tabular}{lllll}
\hline & Freq $^{\mathrm{a}}$. & $\boldsymbol{I}_{\boldsymbol{I R}}^{\boldsymbol{b}}$ & FT-IR $^{[3]}$ & PED $(\%)$ \\
\hline$v_{1}$ & 34 & 0.137 & & \\
$v_{2}$ & 49 & 0.081 & & \\
$v_{3}$ & 62 & 0.658 & & \\
$v_{4}$ & 82 & 0.281 & & \\
$v_{5}$ & 108 & 2.070 & & \\
$v_{6}$ & 130 & 0.528 & & \\
$v_{7}$ & 134 & 0.485 & & \\
$v_{8}$ & 152 & 0.304 & & \\
$v_{9}$ & 165 & 0.071 & & \\
$v_{10}$ & 210 & 0.854 & & \\
$v_{11}$ & 230 & 7.822 & & \\
$v_{12}$ & 254 & 9.932 & & \\
$v_{13}$ & 260 & 19.49 & &
\end{tabular}


Celal Bayar University Journal of Science

Volume 15, Issue 1, 2019, p 119-123

Doi: $10.18466 /$ cbayarfbe.492861

$\begin{array}{lll}v_{14} & 368 & 4.383 \\ v_{15} & 393 & 0.60\end{array}$

$\begin{array}{lll}v_{16} & 475 & 0.247\end{array}$

$\begin{array}{lll}v_{17} & 498 & 2.918\end{array}$

$\begin{array}{lll}v_{18} & 515 & 6.845\end{array}$

$\begin{array}{lll}v_{19} & 709 & 1.826\end{array}$

$\begin{array}{lll}v_{20} & 715 & 0.027\end{array}$

$\begin{array}{lll}v_{21} & 732 & 0.715\end{array}$

$\begin{array}{lll}v_{22} & 765 & 5.648\end{array}$

$v_{23} \quad 797 \quad 47.03$

$\begin{array}{lll}\mathrm{v}_{24} & 802 \quad 81.22\end{array}$

$v_{25} \quad 836 \quad 9.548$

$\begin{array}{lll}v_{26} & 904 & 0.755\end{array}$

$\begin{array}{lll}v_{27} & 930 & 2.610\end{array}$

$\begin{array}{lll}v_{28} & 954 & 1.229\end{array}$

$\begin{array}{lll}v_{29} & 975 & 2.719\end{array}$

$\begin{array}{lll}v_{30} & 987 & 1.514\end{array}$

$v_{31} \quad 998 \quad 6.143$

$\begin{array}{lll}v_{32} & 1023 & 0.280\end{array}$

$\begin{array}{lll}v_{33} & 1028 & 0.515\end{array}$

$\begin{array}{lll}v_{34} & 1031 & 0.283\end{array}$

$v_{35} \quad 1040-3.126$

$v_{36} \quad 1047$

$\begin{array}{lll}v_{37} & 1068 & 2.193\end{array}$

$\begin{array}{lll}v_{38} & 1109 & 1.554\end{array}$

$\begin{array}{lll}v_{39} & 1174 & 0.160\end{array}$

$v_{40} \quad 1190 \quad 0.432$

$\begin{array}{lll}v_{41} & 1212 & 0.101\end{array}$

$\begin{array}{lll}v_{42} & 1231 & 0.105\end{array}$

$\begin{array}{lll}43 & 1252 & 0.181\end{array}$

$\begin{array}{lll}v_{44} \quad 1270 & 0.519\end{array}$

$v_{45} \quad 1282-0.233$

$\begin{array}{lll}\mathrm{V}_{46} & 1291 & 0.122\end{array}$

$v_{47} \quad 1296 \quad 0.042$

$\begin{array}{lll}v_{48} & 1299 & 0.242\end{array}$

$v_{49} \quad 1325-0.572$

$\begin{array}{lll}v_{50} & 1342 & 0.229\end{array}$

$\begin{array}{lll}v_{51} & 1348 & 3.970\end{array}$

$v_{52} \quad 1353$

$\begin{array}{lll}V_{53} & 1356 \quad 1.059\end{array}$

$860 \mathrm{~m}, \mathrm{br} \quad \mathrm{\delta HCH}_{\mathrm{H}}(37 \%)$

$951 \mathrm{vw} \quad \delta_{\mathrm{HCH}}(53 \%)$

$1005 \mathrm{vw} \quad \delta_{\mathrm{CCC}}(27 \%)+\delta_{\mathrm{HNH}}(10 \%)+\delta_{\mathrm{HCH}}(10 \%)$

1052 vw $\quad \delta_{\mathrm{CCH}}(13 \%)+\delta_{\mathrm{HNH}}(13 \%)$

$1075 \mathrm{vw} \quad \delta_{\mathrm{CCH}}(20 \%)+\delta_{\mathrm{HNH}}(18 \%)$

$1089 \mathrm{vw} \quad \delta_{\mathrm{CCC}}(40 \%)+\delta_{\mathrm{HNH}}(13 \%)+\delta_{\mathrm{HCH}}(10 \%)$

$1218 \mathrm{vw} \quad \delta_{\mathrm{CCH}}(48 \%)$

$1305 \mathrm{vW} \quad \delta_{\mathrm{HCH}}(30 \%)+\delta_{\mathrm{HNH}}(18 \%)$

$1338 \mathrm{vw} \quad \delta_{\mathrm{HCH}}(26 \%)+\delta_{\mathrm{HNH}}(21 \%)$

$1367 \mathrm{vw} \quad \delta \mathrm{HCH}(25 \%)+\delta \mathrm{HNH}(18 / \%)$

The NH stretching vibrations appear at $3500-3300 \mathrm{~cm}^{-1}$ $[9,10]$. For 1,8-diaminooctane N-H stretching vibrations are observed at $3381 \mathrm{~cm}^{-1}$ and $3321 \mathrm{~cm}^{-1}$ experimentally (FT-IR spectra) [3] and assigned at $3456 \mathrm{~cm}^{-1}$ and 3452 $\mathrm{cm}^{-1}$ (DFT/B3LYP with $6-311++\mathrm{G}(\mathrm{d}, \mathrm{p})$ ) according to our calculation. It can be seen that in Table 2 , experimental and theoretical results are very consistent with each other.

The asymmetric and symmetric stretching modes of the $\mathrm{CH}_{2}$ group usually occur in the region from 2800 to 3000 $\mathrm{cm}^{-1}$ [11]. In FT-IR spectra for 1,8-diaminooctane C-H stretching vibrations are observed at $2856 \mathrm{~cm}^{-1}$ and 2926 $\mathrm{cm}^{-1}$ experimentally [3]. These vibrations calculated at $2841 \mathrm{~cm}^{-1}$ and $2920 \mathrm{~cm}^{-1}$ by B3LYP/6-311++G(d,p) calculation (Table 2). The theoretical results are very good agreement with experimental ones.

The $\mathrm{H}-\mathrm{C}-\mathrm{H}$ in-plane bending vibrations characterize in the region 1300-1500 $\mathrm{cm}^{-1}$ [12]. Experimentally, the inplane $\mathrm{H}-\mathrm{C}-\mathrm{H}$ bending modes were measured at 1305 , $1338,1367,1390,1440,1466,1487$ and $1584 \mathrm{~cm}^{-1}$ in FTIR spectra [3]. These vibrations calculated at 1299, 1325, $1356,1380,1437,1464,1471$ and $1604 \mathrm{~cm}^{-1}$ by means of B3LYP/6-311++G (d,p) (Table 2). It can be seen that in Table 2, experimental and theoretical results are very consistent with each other.

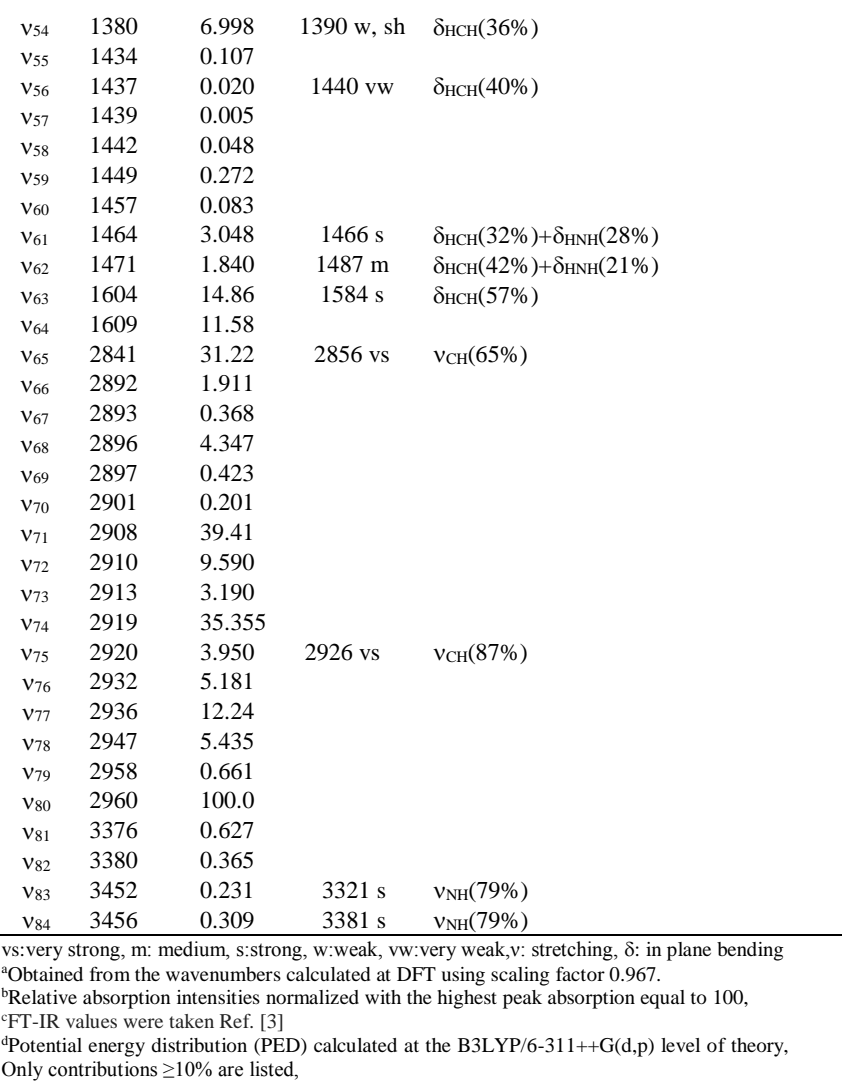

The C-C-H in-plane bending vibrations appear in the region $1300-1000 \mathrm{~cm}^{-1}$ [12]. Experimentally, the in-plane C-C-H bending modes were measured at 1052, 1075, 1089 and $1218 \mathrm{~cm}^{-1}$ in FT-IR spectra [3]. These vibrations calculated at 1047, 1068, 1109 and $1212 \mathrm{~cm}^{-1}$ by means of B3LYP/6-311++G (d,p) (Table 2). It can be seen that in Table 2, experimental and theoretical results are very compatible.

All aromatic C-H stretching vibrations were found to be weak. This reason may be attributed to decrease in the dipole moment because of decrease the negative charge on the $\mathrm{C}$ atom [13]. This decrease is due to the withdrawing of electrons from the carbon atom of the molecule due to the reduction of inductive effect, resulting in an increase in the chain length of the molecule [13].

\section{HOMO-LUMO analysis}

The highest occupied molecular orbital (HOMO), the lowest unoccupied molecular orbital (LUMO) and HOMO-LUMO energy gaps have been performed with using DFT at B3LYP/6-311++G(d,p) level. They are very important parameters in quantum chemistry. HOMO defines the ability to donate an electron and LUMO defines the ability to obtain an electron. The plots of HOMO, HOMO-1, LUMO, LUMO+1 for 1,8diaminooctane were given in Figure 5. The HOMOLUMO energy gap $(\Delta E)$ value of 1,8-diaminooctane calculated as $6.18 \mathrm{eV}$. This value for Urea $6.72 \mathrm{eV}$ in the 
literature [14]. So, 1,8-diaminooctane is very soft molecule and very stable than Urea molecule.

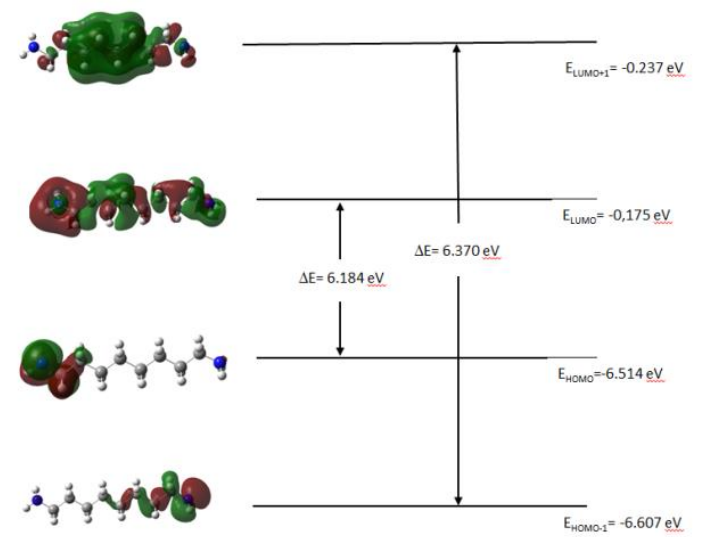

Figure 5. Frontier molecular orbitals of 1,8 diaminooctane.

Besides, dipole moment values of 1,8-diaminooctane calculated by DFT and these values are given in Table 3 .

Table 3. The dipole moment (field-independent basis, Debye) values of 1,8-diaminooctane.

\begin{tabular}{cccc}
\hline $\boldsymbol{\mu}_{\boldsymbol{x}}$ & $\boldsymbol{\mu}_{\boldsymbol{y}}$ & $\boldsymbol{\mu}_{\boldsymbol{z}}$ & $\boldsymbol{\mu}_{\text {tot }}$ \\
-1.21 & 1.62 & 1.07 & 2.29 \\
\hline
\end{tabular}

\section{MEPS of 1,8-diaminooctane}

The molecular electrostatic potential (MEP) maps of 1,8diaminooctane's ground state are shown in Figure f. $^{5}$. Using the B3LYP/6-311++G(d,p) level of theory, the MEP maps were drawn. The MEP can be seen as reactivity maps on organic molecules, showing the most likely regions where point charges can approach the molecule. The MEP is used for researching reactivity regions. In MEP maps, red color shows negative, blue color shows positive areas. In Figure 6 right side picture, MEP in 1,8-diaminooctane is mainly over Nitrogen atoms.

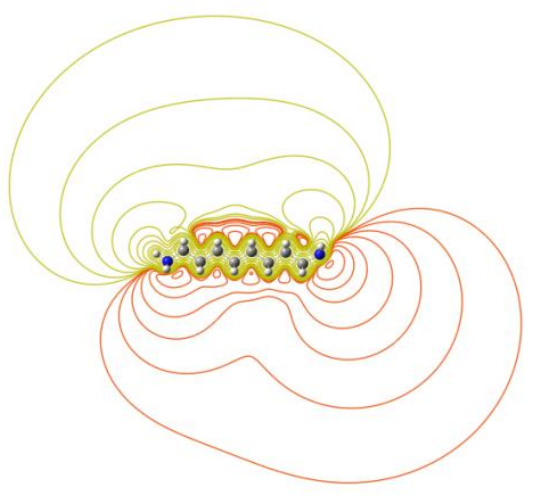

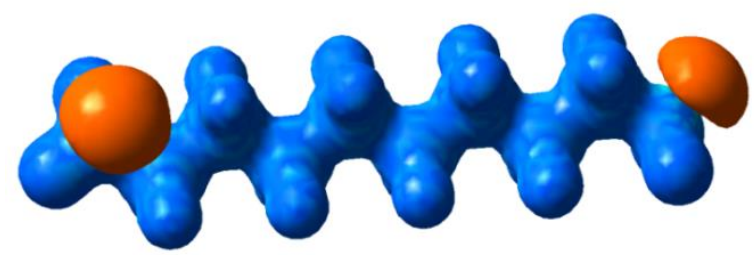

Figure 6. The MEP maps of 1,8-diaminooctane

\section{Conclusion}

In this work, the geometrical parameters, vibrational frequencies, dipole moments, HOMO-LUMO and MEP of 1,8-diaminooctane were performed with using Gaussian $03 \mathrm{~W}$ program. In that all theoretical calculations, we used B3LYP/6-311++G(d,p) level of theory. The calculated geometrical structural and vibrational spectral data of 1,8-diaminooctane with DFT methods are good consistent with available experimental data.

\section{Author's Contributions}

Akif Özbay: Drafted and wrote the manuscript, performed the experiment and result analysis.

Aysun Gözütok: Assisted in analytical analysis on the structure, supervised the experiment's progress, result interpretation and helped in manuscript preparation.

\section{Ethics}

There are no ethical issues after the publication of this manuscript.

\section{References}

1. Chemical Entities of Biological Interest (ChEBI) UK, http://www.ebi.ac.uk/chebi/searchId.do?chebiId=CHEBI:73112 (accessed at 01.06. 2018).

2. Sigma Aldrich Chemical Company, https://www.sigmaaldrich.com/catalog/product/aldrich/d22401?la $\mathrm{ng}=\mathrm{en} \&$ region=TR (accessed at 01.06. 2018).

3. Kasap, E, Özbay, A. 1997. Infrared spectroscopic study of the Hofmann -daon-type clathrates : $\mathrm{M}(1,8$ diaminooctane $) \mathrm{Ni}(\mathrm{CN})_{4} \cdot \mathrm{G}(\mathrm{M}=\mathrm{Co}, \mathrm{Ni}$ or $\mathrm{Cd} ; \mathrm{G}=$ Aromatic Guest Molecules). Journal of Inclusion Phenomena and Molecular Recognition in Chemistry; 28: 335-347.

4. Frisch, A, Dennington, RD, Keith, TA, Nielsen, AB, Holder, AJ. 2003. GaussView 3.0, Gaussian, Inc., Wallingford CT.

5. Frisch, MJ, Trucks, GW, Schlegel, HB, Scuseria GE, Robb, MA, Cheeseman, JR, Zakrzewski, VG, Montgomery, JA, Stratmann, Jr RE, Burant, JC, Dapprich, S, Milliam, JM, Daniels, AD, Kudin, KN, Strain, MC, Farkas, O, Tomasi, J, Barone, V, Cossi, M, Cammi, R, Mennucci, B, Pomelli, C, Adamo, C, Clifford, S, Ochterski, J, Petersson, GA, Ayala, PY, Cui, Q, Morokuma, K, Malick, DK, Rabuck, AD, Raghavachari, K, Foresman, JB, Cioslowski, J, Ortiz, JV, Baboul, AG, Stefanov, BB, Liu, G, Liashenko, A, Piskorz, P, Komaromi, I, Gomperts, R, Martin, RL, Fox, DJ, Keith, T, Al-Laham, MA, Peng, CY, Nanayakkara, A, Challacombe, M, Gill, PMW, Johnson, B, Chen, W, Wong, MW, Andres, JL, Gonzalez, C, Head-Gordon, M, Replogle, ES, Pople, JA. Gaussian, Inc., Wallingford CT, 2004. 
6. Scaling factor, https://cccbdb.nist.gov/vibscalejust.asp (accessed at 01.06. 2018)

7. Meng, XG, Lin, ZD. 2005. Catena- Poly[[tetraaquacadmium(II)$\mu$-hexane-1,6-diamine- $\left.\kappa^{2} \mathrm{~N}: \mathrm{N}^{\prime}\right]$ terephthalate dihydrate]. Acto Crystallographica E; 61: 263-264.

8. Pulay, P, Baker, J, Wolinski, K. 2013. Green Acres Road Suite A Fayettevile, Arkansas, 72703, USA.

9. Spire, A, Barthes, M, Kellouai, H, De Nunzio G. 2000. Far-infrared spectra of acetanilide. Physica D:Nonlinear Phenomena; 137: 392 -396 .

10. Panicker, CY, Varghese, HT, Thansani, T. 2009. Spectroscopic studies and Hartree-Fock ab initio calculations of a substituted amide of pyrazine-2-carboxylic acid- $\mathrm{C}_{16} \mathrm{H}_{18} \mathrm{ClN}_{3} \mathrm{O}$. Turkish Journal of Chemistry; 33: 633 - 646.
11. Sajan, D, Binoy, J, Pradeep, B, Venkatakrishnan, K, Kartha, VB, Joe, IH, Jayakumar, VS. 2004. NIR-FT Raman and infrared spectra and ab initio computations of glycinium oxalate. Spectrochimica Acta Part A: Molecular and Biomolecular Spectroscopy; 60: 173-180.

12. Thilagavathi, G, Arivazhagan, M. 2010. Density functional theory calculation and vibrational spectroscopy study of 2-amino-4,6dimethyl pyrimidine (ADMP). Spectrochimica Acta Part A: Molecular and Biomolecular Spectroscopy; 79: 389 - 395.

13. Shanmugam, R, Sathyanarayana, D. 1984. Experimental (FT-IR and FT-Raman), electronic structure and DFT studies on 1methoxynaphthalene. Spectrochimica Acta Part A: Molecular and Biomolecular Spectroscopy; 40: 757 - 761.

14. Tesch, MF, Golnak, R, Ehrhard, F, Schön, D, Xiao, J, Atak K, Bande, A, Aziz, EF. 2016. Analysis of the Electronic structure of aqueous urea and its derivatives: a systematic soft X-Ray-TD-DFT approach. Chemistry; 22: 12040. 